\title{
Center-Slotted Wideband Hybrid 10 dB Coupler
}

\section{DOI : 10.36909/jer.13313}

\author{
Sehabeddin Taha Imeci *, Kemal Temur ** \\ * Department of Electrical and Electronics Engineering, Fatih Sultan Mehmet Foundation \\ University, Turkiye \\ **Department of Electrical and Electronics Engineering, Faculty of Engineering and Natural \\ Sciences, International University of Sarajevo, Bosnia and Herzegovina \\ *Email: simeci@ius.edu.ba; Corresponding Author.
}

\begin{abstract}
In this paper, a wideband microstrip hybrid coupler designed, simulated, built and tested. These couplers have advantage of easy fabrication, lightweight and incorporation with other microwave devices and validated using 3D planar electromagnetic softwares like Sonnet Suites. The final design is composition of two parallel lines with symmetric slits and a center slot. Directional coupler is designed and simulated to operate in the frequency range from 1 $\mathrm{GHz}$ to $5 \mathrm{GHz}$ with $2.4 \mathrm{Ghz}$ coupling $-10 \mathrm{~dB}$ return loss bandwidth between $1.6-4 \mathrm{GHz}$. The fabricated coupler shows good agreement between measured and simulated results with very low isolation characteristics. Four symmetric orthogonal U-Shaped structures at the center of the coupling region distinguishes the proposed design with other works. It makes significant improvement in calculation duration thereby achieving lower response latency and lowers the possible manufacturing errors compared with previously published similar works.
\end{abstract}

Keywords: Sonnet software, Directional Coupler, Microstrip, Hybrid, 10 dB. 


\section{INTRODUCTION}

Microstrip directional couplers with two parallel signal lines are used in RF filter and various microwave integrated routing devices for isolating, separating. (Chang et al, 2004). Directional couplers are passive devices used for sampling, in the field of radio technology, power splitters or power combiners. Directional couplers are one of the most often used devices of Microwave power for measurement purposes (Abbas et al, 2013). However, inhomogeneous air transmission lines and dielectric substrate make the directional coupler a weak device from its orientation (Kim et al, 2007). To improve the directivity, some approaches include symmetrical across the coupled arms at the center and the utilization of active devices. (Sohn et al, 2016). If two transmission lines are close to each other, these are extensively known as quad couplers because a $90^{\circ}$ phase diffrence between its two output ports. (Muller et al, 2010). Some similar works of $10 \mathrm{~dB}$ couplers use conventional brancline structure with DGS (defected ground structure) which requires higher fabrication costs. Our design has an advantage because it has very simple orthogonal $U$ shaped metals and full metal ground. (Tamasi et. al, 2012) Many projects require a wide bandwidth, the solution for this is to use coupled stripline circuits. To increase the bandwidth of a coupler, the first multi-section configuration is preferred by (Mousavi et al, 2015). A recent work of $10 \mathrm{~dB}$ high frequency microstrip coupler is presented for motion detection sensor (Giovanni et al. 2018). They have two conventional designs having only $1 \mathrm{GHz}$ bandwidth in X-Band. Easier solution to achieve broader bandwidth is to use symmetrical coupler, which is presented here. $10 \mathrm{~dB}$ couplers are quite commonly used. In this project, the main purpose was to design high directivity characteristics of a microstrip coupler. Details of the work with parametric studies and the simulated-measured results are discussed, and figures-tables presented (Imeci et al, 2011). There are very high frequency $10 \mathrm{~dB}$ coupler designs operating from $325 \mathrm{GHz}$ to $400 \mathrm{GHz}$ 
based on the short-slot Riblet-type coupling configuration and fabricated using the deep reactive ion etching (DRIE) silicon micromachining technique in literature but those are beyond the scope of the proposed design (Hu et al. 2015).

\section{COUPLER DESIGN}

The coupler in this study is designed in Sonnet software which is made up of 4 ports located in each four sides of the structure to maintain easy measuring capabilities in the Lab and better housing specs while connecting to other devices. The coupling region of the structure is symmetric in order to maintain the reciprocity. In this work, we used some of the following properties and methods. Some geometrical values were changed in order to prove that our configuration will work properly in different applications.

The material used fort he substrate is FR4 $\left(\varepsilon_{r}=4.4\right)$. The thickness of dielectric layer is used as $1.55 \mathrm{~mm}$. The top and 3D view of the microstrip directional coupler is shown in Fig. 1 and Fig. 2.

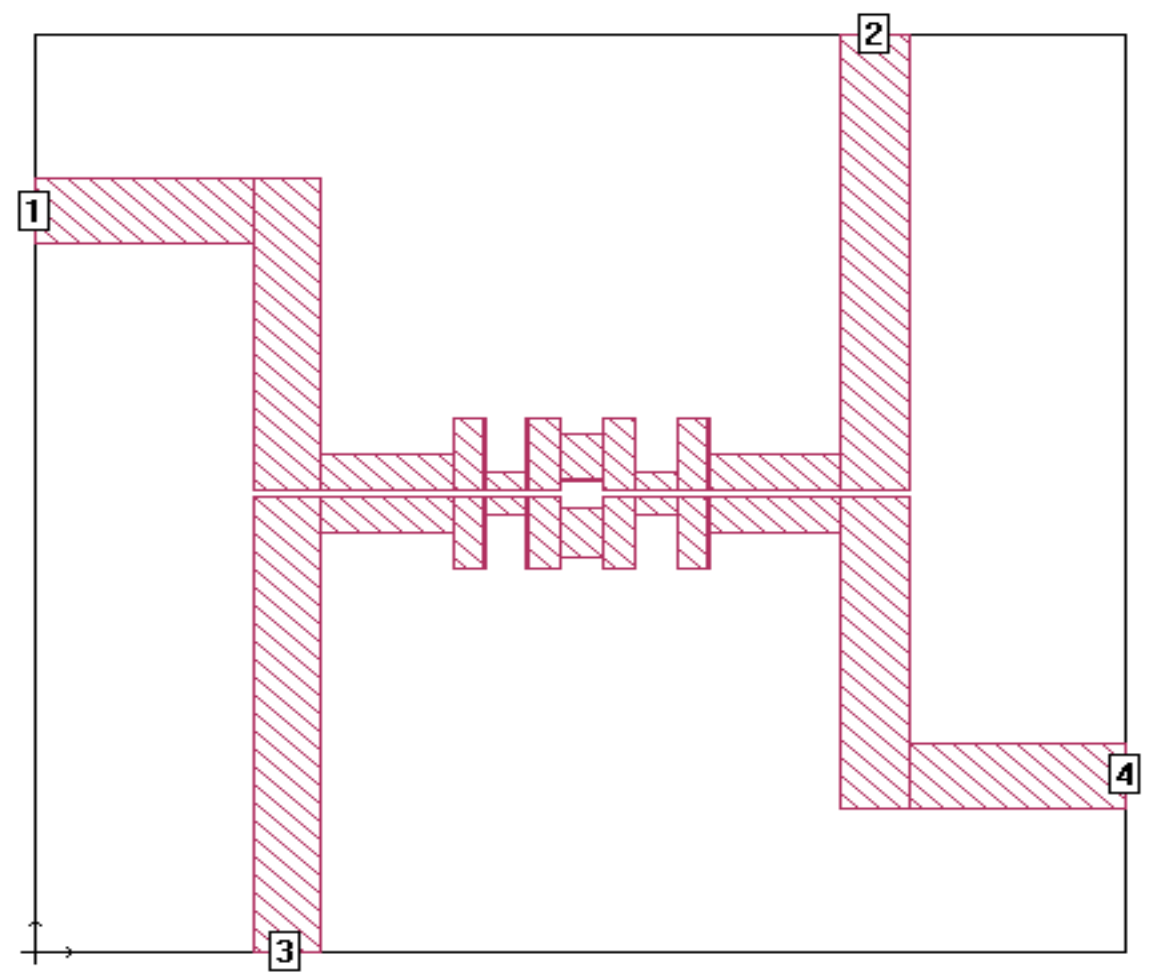

Figure 1 The top view of the coupler 


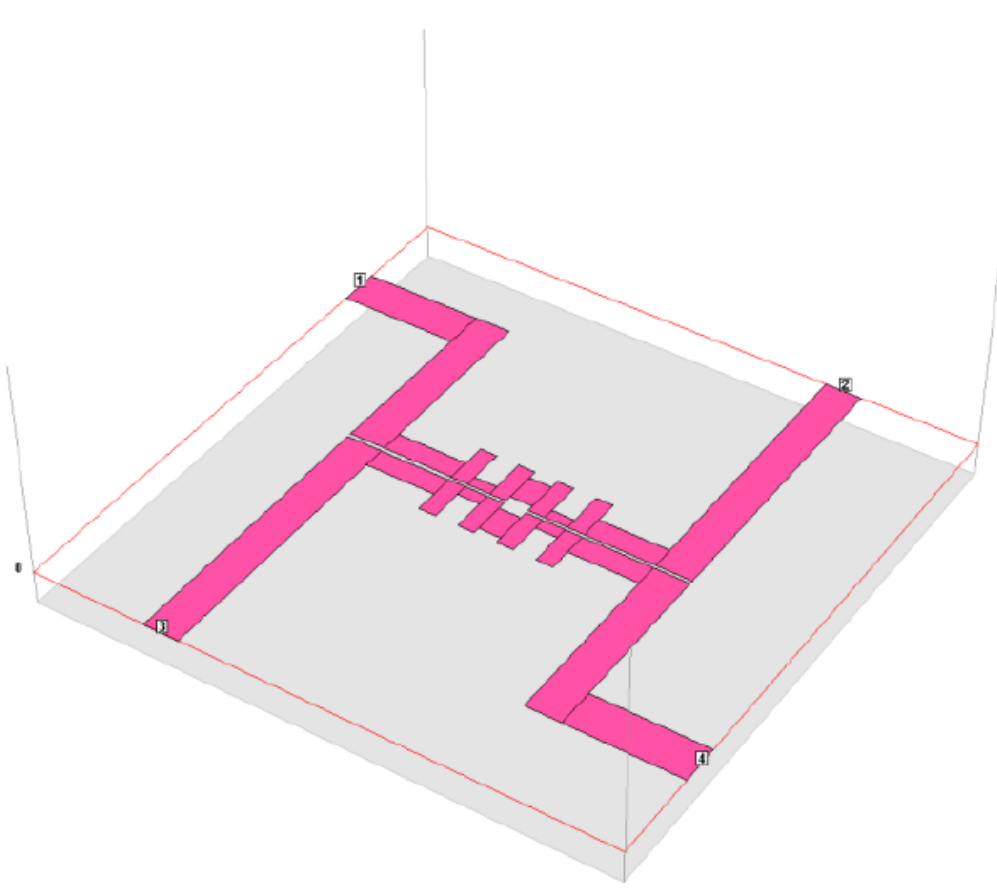

Figure 23D view of the coupler

For a single section coupler the odd and even mode characteristic impedances are defined. When normalized to the charteristic impedance of the input ports and isolation of the coupler ensure,

$$
Z_{0}=\sqrt{Z_{0 e} Z_{0 o}} \Omega \text { Normalizes } z_{0 e} Z_{0 o}=1
$$

$\mathrm{K}$ is the coupling coefficient of coupled line section which is given by (2). The coupling factor can then be calculated as (Salem et al, 2006).

$$
k=\frac{Z_{0 e}-Z_{0 o}}{Z_{0 e}+Z_{0 o}} \quad \text { or } \quad C_{d B}=20 \log k \quad(2),(3)
$$

In another saying, ideal coupler is lossless, reciprocal and matched 4-port device, and the Sparameters are shown in equation 4 below (Imeci et al, 2010). Figure 3 has the schematic of the coupler.

$$
S=\left[\begin{array}{cccc}
0 & S_{12} & 0 & S_{14} \\
S_{21} & 0 & S_{23} & 0 \\
0 & S_{32} & 0 & S_{34} \\
S_{41} & 0 & S_{43} & 0
\end{array}\right]
$$


The purpose of designing couplers is to achieve low input match and high directionality at the desired frequency. The $\mathrm{ABCD}$ matrix is intoduced to analyze the overall transmission and reflection characteristics of the network

$$
\begin{aligned}
& {\left[\begin{array}{ll}
A & B \\
C & D
\end{array}\right]_{e}=\left[\begin{array}{cc}
\beta_{e} & j Z_{o e} a_{e} \\
j Y_{o e} a_{e} & \beta_{e}
\end{array}\right]\left[\begin{array}{cc}
A & B \\
C & D
\end{array}\right]_{o}} \\
& =\left[\begin{array}{cc}
\beta_{o}-w 2 C Z_{o o} a_{o} & j Z_{o o} a_{o} \\
l\left(4 w C_{c} \beta_{o}+Y_{o o}-4 w^{2} C^{2}\right. & \beta-w 2 C_{c} Z_{o o} a_{o}
\end{array}\right]
\end{aligned}
$$

Where $a_{c}=\sin \left(\theta_{e}\right), a_{o}=\sin \left(\theta_{o}\right), \beta_{e}=\cos \left(\theta_{e}\right)$ and $\beta_{o}=\cos \left(\theta_{o}\right)$.Assuming $\theta_{e}=\frac{\pi}{2}, C_{c}$ for zeroing the value of $A_{o}$ and $D_{o}$ can be found in 7, and the compensanting odd-mode chatacteritic impedance yield (Baek et al, 2008);

$$
C=\frac{c_{i n}\left(\theta_{o}\right)}{2 w Z_{o o}}, Z_{o o c}=Z_{o o} \sin \left(\theta_{o}\right)
$$

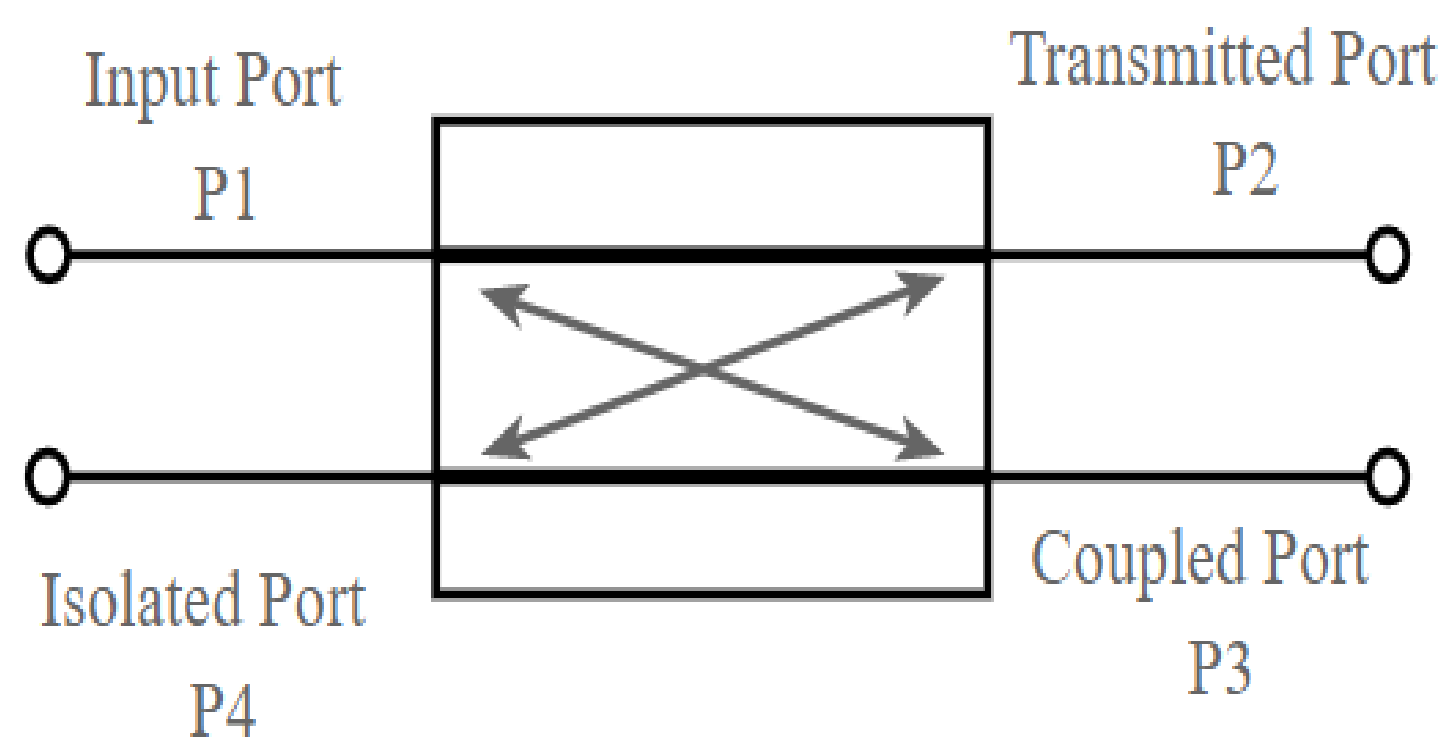

Figure 3 Four Port Microstrip Directional Coupler 
Coupling shows how much of incident power is being sampled at the coupled port and directivity is a measure of how well the coupler distinguishes between forward and reverse traveling waves

$$
\begin{aligned}
& \text { Coupling Factor }(\mathrm{dB})=10 \log \frac{P_{1}}{P_{3}} \\
& \text { Insertion loss }(\mathrm{dB})=10 \log \left[1-\frac{P_{3}}{P_{1}}\right]
\end{aligned}
$$

$P_{1}$ is the ratio of input and $P_{3}$ is power to the output power from the coupled port.

Isolation is sometimes used to describe the "directive" property. It is the ratio of input $P_{1}$ to the isolated $P_{4}$, measured in $\mathrm{dB}$ (Asdhar et al, 2018)

$$
\text { Isolation }(\mathrm{dB})=-10 \log \frac{P_{4}}{P_{1}} \text {. }
$$

Even and odd-mode effective permittivities of microstrip couplers are calculated as follows

$$
\begin{aligned}
& \varepsilon_{e f f e}=\frac{C_{e}}{C_{e 1}} \\
& \varepsilon_{e f f o}=\frac{C_{o}}{C_{o 1}}
\end{aligned}
$$

In order to find the stored energy of microstrip couple using FE calculation,

$$
W=\frac{1}{2} \int \varepsilon_{0} \varepsilon_{r} \nabla u \nabla u d S
$$

$\varepsilon_{0}$ is the permittivity of free space, $\varepsilon_{r}$ is relative permittivity, $u$ means the electric potential.

From equation 13, the capacitance is then found as

$$
C=\frac{2 W}{(\nabla u)^{2}}
$$

\section{ANALYSIS AND SIMULATION RESULTS}

Figure 4 shows the results obtained by simulation of the center-slotted wideband hybrid coupler in Sonnet Software with coupling of -10 dB (S13) (Sonnet Suites, 2013). Simulations 
were performed with planar 3D electromagnetic tool. Cell size is reduced in order to get optimum simulation result. The sidewalls are far enough from the coupling section to avoid reflection of the shielded box. The air layer above the coupler, which makes the design as microstrip, is at least 3 times higher than the substrate thickness to clear the potential box resonances. The characteristic impedance of the conventional couplers is $50 \Omega$ (Tian et al, 2001). Figure 4 has the $S$ parameters of the coupler. In this graph its shown the values of the parameters of S11 (the input match), S12 (thru port), S13 (coupling), and S14 (isolation). As we can see from this figure, insertion loss is $-1 \mathrm{~dB}$, input match is less than $-18 \mathrm{~dB}$ and isolation is less than $-21 \mathrm{~dB}$ throughout the working band of $1.6-4 \mathrm{GHz}$. Figure 5 shows the angle is 90 degrees between the coupled and thru ports, which proves this is a 90 degree hybrid coupler.

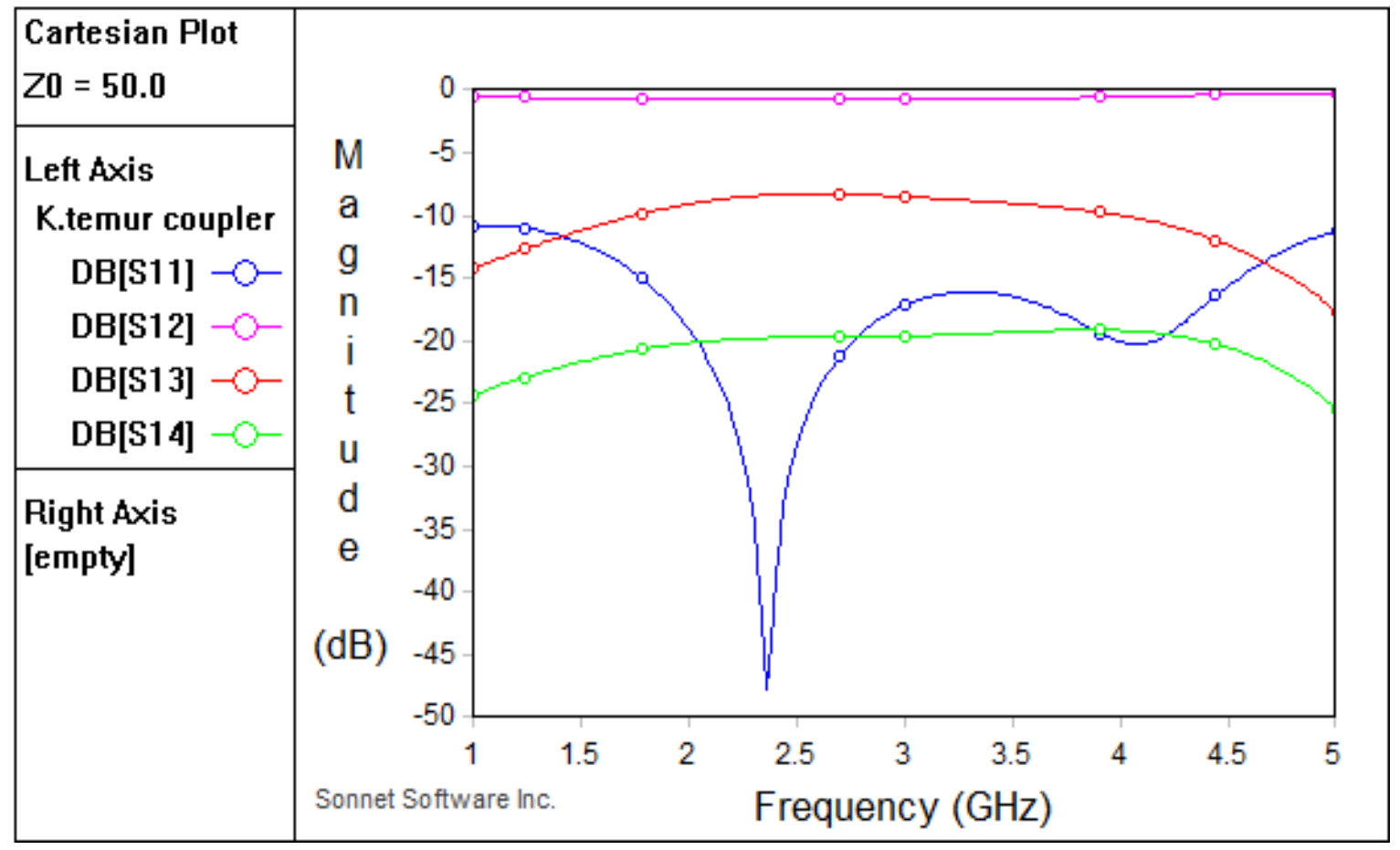

Figure 4 S-parameter of the Coupler 


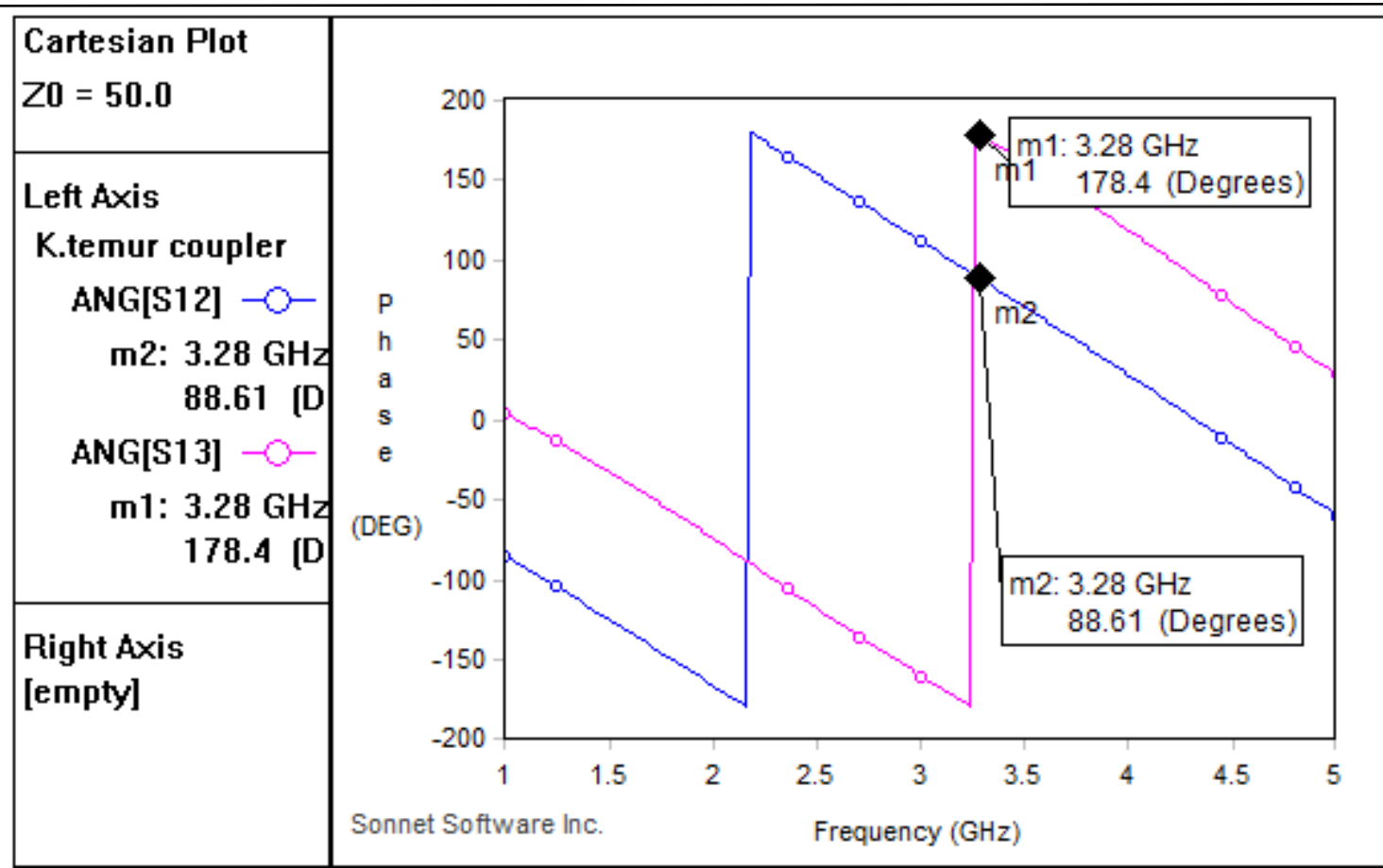

Figure 5 Angle between the Coupled and Through ports.

Table 1, Table 2, and Table 3 are presenting the parametric study of coupling bandwidth and coupling amplitude balance by changing the width of the separation, thickness of dielectric and constrant of the dielectric (Yildiz et al, 2020). The fequency bandwith is $2.4 \mathrm{GHz}$ between 1.6-4 GHz. Table 1 shows the amplitude balance of the coupling (Yuksel et al, 2012) is increasing when separation is increased by $0.1 \mathrm{~mm}$ (Imeci, 2017). Table 2 and 3 show that the fabrication tolerances of the lossy dielectric FR4 is fair enough. Table 4 gives comparison of proposed design with those found in literature and listed in references.

Table 1 Comparison of the separation between the Lines

\begin{tabular}{|c|c|c|c|}
\hline $\begin{array}{c}\text { Spacing Between the } \\
\text { Lines }(\mathrm{mm})\end{array}$ & $\begin{array}{c}\text { Frequency Bandwidth } \\
(2.4 \mathrm{GHz})\end{array}$ & $\begin{array}{c}\text { Coupling Port } \\
(\mathrm{dB})\end{array}$ & $\begin{array}{c}\text { Amplitude Balance } \\
(\mathrm{dB})\end{array}$ \\
\hline \multirow{2}{*}{0.2} & 1.6 & -10.73 & \multirow{2}{*}{0.72} \\
\cline { 2 - 3 } & 4 & -10.01 & \multirow{2}{*}{0.98} \\
\hline \multirow{2}{*}{0.3} & 1.6 & -11.91 & \\
\cline { 2 - 4 } & 4 & -10.93 & 1.19 \\
\hline
\end{tabular}




\begin{tabular}{|c|c|c|c|}
\hline & 4 & -11.75 & \\
\hline \multirow{3}{*}{0.5} & 1.6 & -13.87 & \multirow{2}{*}{1.35} \\
\cline { 2 - 3 } & 4 & -12.52 & \\
\hline
\end{tabular}

Table 2 Comparison of the Dielectric Thickness

\begin{tabular}{|c|c|c|c|}
\hline $\begin{array}{l}\text { Dielectric Thickness } \\
(\mathrm{mm})\end{array}$ & $\begin{array}{l}\text { Frequency Bandwidth } \\
\qquad(\mathrm{GHz})\end{array}$ & $\begin{array}{l}\text { Coupling Port } \\
\text { (dB) }\end{array}$ & $\begin{array}{l}\text { Amplitude Balance } \\
\text { (dB) }\end{array}$ \\
\hline \multirow[t]{2}{*}{1.45} & 1.6 & -10.73 & \multirow{2}{*}{0.72} \\
\hline & 4 & -10.01 & \\
\hline \multirow[t]{2}{*}{1.50} & 1.6 & -10.6 & \multirow[t]{2}{*}{0.75} \\
\hline & 4 & -9.85 & \\
\hline \multirow[t]{2}{*}{1.60} & 1.6 & -10.49 & \multirow[t]{2}{*}{0.79} \\
\hline & 4 & -9.70 & \\
\hline \multirow[t]{2}{*}{1.65} & 1.6 & -10.37 & \multirow[t]{2}{*}{0.81} \\
\hline & 4 & -9.56 & \\
\hline
\end{tabular}

Table 3 Comparison of the Dielectric Constant

\begin{tabular}{|c|c|c|c|}
\hline $\begin{array}{c}\text { Dielectric Constrant } \\
\left(\varepsilon_{r}\right)\end{array}$ & $\begin{array}{c}\text { Frequency } \\
\text { Bandwidth }(\mathrm{GHz})\end{array}$ & $\begin{array}{l}\text { Coupling Port } \\
(\mathrm{dB})\end{array}$ & $\begin{array}{l}\text { Amplitude Balance } \\
(\mathrm{dB})\end{array}$ \\
\hline \multirow[t]{2}{*}{4.3} & 1.6 & -10.73 & \multirow{2}{*}{0.72} \\
\hline & 4 & -10.01 & \\
\hline \multirow[t]{2}{*}{4.35} & 1.6 & -10.68 & \multirow[t]{2}{*}{0.6} \\
\hline & 4 & -10.08 & \\
\hline \multirow[t]{2}{*}{4.45} & 1.6 & -10.65 & \multirow[t]{2}{*}{0.5} \\
\hline & 4 & -10.15 & \\
\hline \multirow[t]{2}{*}{4.50} & 1.6 & -10.6 & \multirow[t]{2}{*}{0.38} \\
\hline & 4 & -10.22 & \\
\hline
\end{tabular}


Table 4 Advantages and disadvantages of our designs with compared to the different couplers

\begin{tabular}{|c|c|c|}
\hline Our and Prior designs & Advantages & Disadvantages \\
\hline Our proposed design & $\begin{array}{l}\text { - wideband with relatively cheap } \\
\text { cost, compact size } \\
\text { - good isolation and directivity } \\
\text { with amplitude balance less than } 1 \\
\text { dB }\end{array}$ & $\begin{array}{l}\text { - Tangent losses } \\
\text { caused by the FR4 } \\
\text { substrate. }\end{array}$ \\
\hline $\begin{array}{l}\text { Sohn, S.M. et all, A Compact } \\
\text { high power canable and tunable } \\
\text { high directivity microstrip } \\
\text { coupler }\end{array}$ & $\begin{array}{l}\text { - simple and cheap to manufacture } \\
\text { - high directivity ( over } 40 \mathrm{~dB} \text { ) }\end{array}$ & - very low frequency \\
\hline $\begin{array}{l}\text { G. A, Asdhar et al, T-Junction } \\
\text { branch line coupler with notch } \\
\text { band filter for radar S-band } 3 \\
\text { GHz. }\end{array}$ & $\begin{array}{l}\text { - simple branchline design } \\
\text { - good for radar applications }\end{array}$ & $\begin{array}{l}\text { - Lossy dielectric } \\
\text { FR4 } \\
\text {-works only in one } \\
\text { narrow band, } 3 \mathrm{GHz}\end{array}$ \\
\hline $\begin{array}{l}\text { Sorocki, J., et al. 2020. Low- } \\
\text { Cost microwave components } \\
\text { fabrication in hybrid } \\
\text { technology of laminates and } \\
\text { additive manufacturing on an } \\
\text { example of miniaturized } \\
\text { suspended directional coupler }\end{array}$ & $\begin{array}{l}\text { - good housing options with four } \\
\text { ports located each sidewalls } \\
\text { - compatible with state of the art } \\
\text { 3-D printing technology }\end{array}$ & $\begin{array}{l}\text { - hard to manufacture } \\
\text { because of stripline } \\
\text { structure } \\
\text { - lower bandwidth }\end{array}$ \\
\hline $\begin{array}{l}\text { Mousavi, S.M., et al. } 2015 \text {. } \\
\text { Design fabrication and test of a } \\
\text { broadband high directivity } \\
\text { directional coupler. }\end{array}$ & $\begin{array}{l}\text { - ultra broadband } \\
\text { - very high frequency (millimeters } \\
\text { wave region) }\end{array}$ & $\begin{array}{l}\text { - hard to manufacture } \\
\text { due to stripline } \\
\text { technology and short } \\
\text { pins }\end{array}$ \\
\hline
\end{tabular}

\section{FABRICATION AND MEASURED RESULTS}

Computer numerical control machine processed a design of microstrip directional coupler by control milling technique and following a coded programme. (Nasri et al, 2020). The coupler were fabricated on FR 4 substrate with $\varepsilon_{\mathrm{r}}=4.4$ and $1.55 \mathrm{~mm}$ thickness. SMA connectors directly soldered in the edges of the coupler's four ports and the metal ground layer (Sorocki et al, 2020). Fabricated coupler is seen in Figure 6. The S parameters of the Center-Slotted Wideband Hybrid $10 \mathrm{~dB}$ coupler is measured by the Network Analyser in the Microwave Laboratory as seen in figure 7 . Figure 7 shows that the two ports were terminated with 50 ohms while the other two ports were connected to the probes of the Network Analyzer. This 
process were applied to all ports and required $S 4 p$ files were obtained by the Network Analyzer.

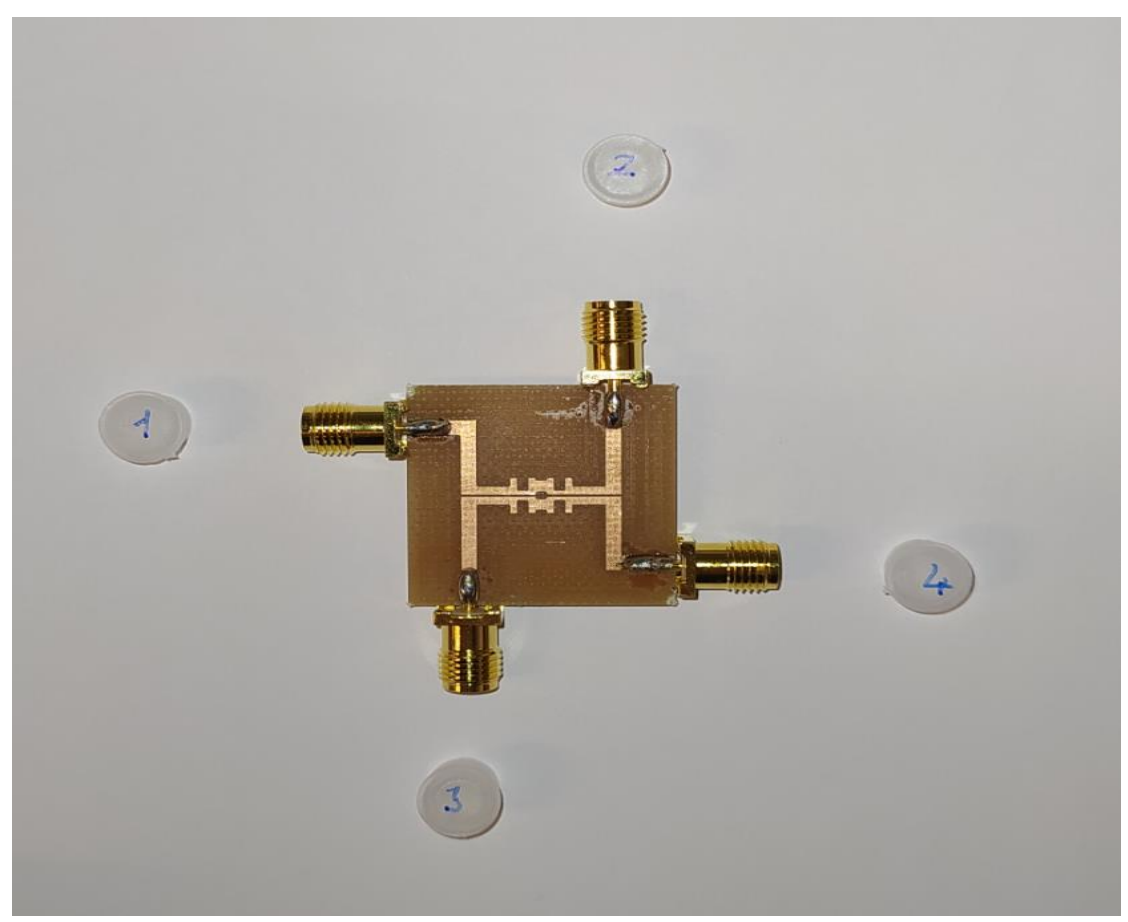

Figure 6 Top view of the Fabricated Design

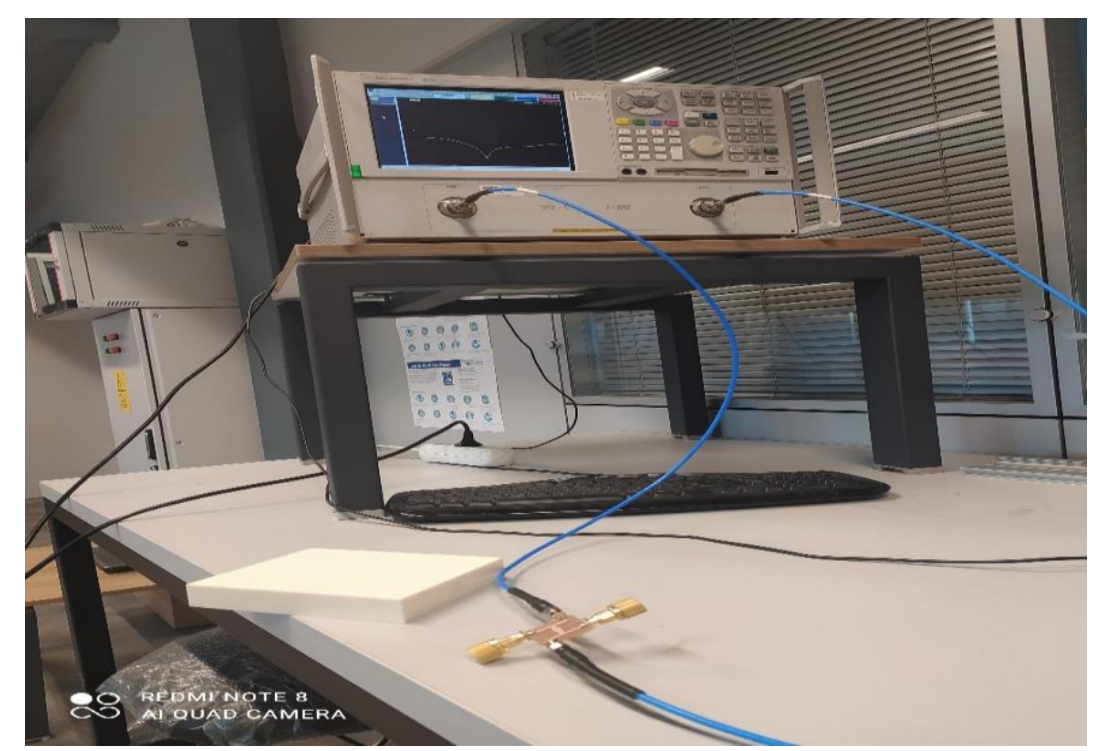

Figure 7 Coupler connected to Network Analyser 
Figure 8 shows S11, S12, S13, S14 curves of the simulated and measured parameters of Center-slotted wideband hybrid $10 \mathrm{~dB}$ coupler. Simulation and measurement have almost the same results (Tutuncu et al, 2019). Especially having less than $1 \mathrm{~dB}$ of amplitude balance between the $1.6-4 \mathrm{GHz}(2.4 \mathrm{GHz}$ wide bandwidth) proves the novelty mentioned in the abstract. This is due to the simple orthogonal and symmetric U-shaped geometry of the couplers main center section.

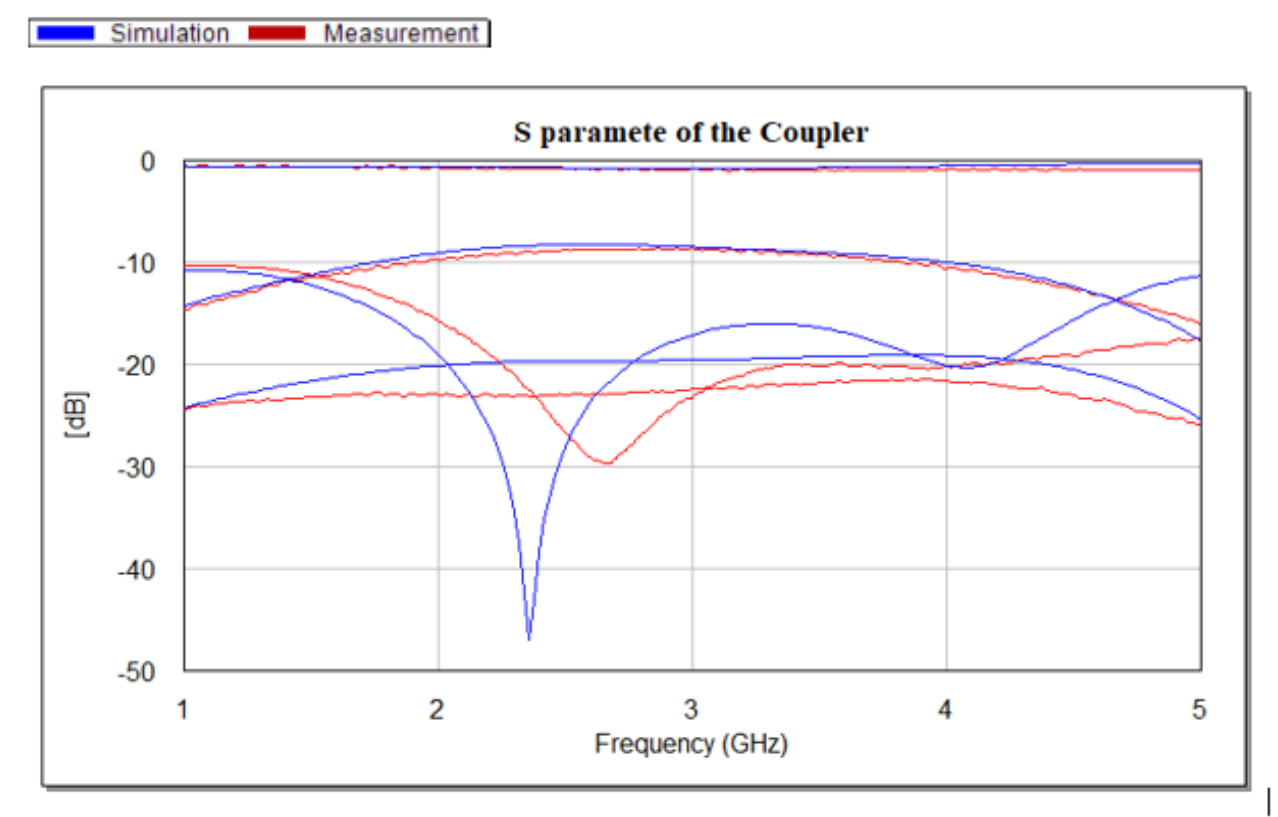

Figure 8 Simulated and Measured S-parameters of the coupler

\section{CONCLUSION}

Microstrip hybrid couplers are implemented for realizing the high directivity and isolation characteristics with desired coupling values. The proposed $10 \mathrm{~dB}$ coupler meets the requirements for a coupler which has great performances and economical with its low cost material used and simple geometrrical design. The results were compared with tolerance analysis of the dielectric thickness, dielectric constant and separation distance between lines and show decent results within the working band between 1.6 - $4 \mathrm{GHz}$. According to the simulation results of Sonnet Suites, all results are satisfactory (Dalar et al, 2012). The 
fabricated couplers S-parameters is measured by the Network Analyser at Microwave Laboratory. The measurement results show vey good agreement with the simulation results.

\section{ACKNOWLEDGEMENT}

We would like to thank Sonnet Software for their services of providing the home licencing during the pandemic, International University of Sarajevo Research and Development Center for fabrication and Istanbul Technical Universities Microwave Laboratory for measurements.

\section{REFERENCES}

Chang, S.F, Chen, J.L, Jeng, Y.H and Wu, C.T. 2004. New high-directivity coupler design with coupled spurlines. IEEE Microwave and Wirrless Components Letters 14(2).

Abbas, S.U, Strener, S.M., and Oberhammer, J. 2013. High-directivity MEMS-tunable directional couplers for 10-18 GHz broadband applications. IEEE Transactions on Microwave Theory and Techniques, 61(9): 3236-3246.

Kim, C.S., Kim, Y.T., Song, S.H., Jung, W.S., Kang, K.Y., Park, J.S., and Ahn, D. 2007. A Design of microstrip directional coupler for high directivity and tight coupling. IEEE Microwave Conference, 31st European, 10.1109/EUMA.2001.339173.

Sohn, S.M., Gopinath, A., and Vaughan, J.T. 2016. A Compact high power canable and tunable high directivity microstrip coupler. IEEE Trans Microw Theory Tech, 64(10):32173223.

Muller, J. and Jacob, A.F. 2010. Advanced characterization and design of compensated high directivity quadrature coupler. IEEE 978-1-4244-7732.

Tamasi M, Arabinda R, Parui SK, Santanu D, 2012, Design of $10 \mathrm{db}$ Branchline coupler by using DGS, Int. Conf. on Communications, Devices and Intelligent Systems (CODIS)

Mousavi, S.M., Mirtaheri, S.A., Khosravani, M.A., Habibi, M.B., and Meiguni, J.S. 2015. Design fabrication and test of a broadband high directivity directional coupler. Electrical 
Engineering (ICEE), 23rd Irannian Conference on At Tehran, Iran, 10.1109/IranianCEE.2015.7146203.

Giovanni M., Giorgio M, Zushen J, Alessandro F, Giovanni AC. 2018 Design of a LowCost Microstrip Directional Coupler with High Coupling for a Motion Detection Sensor, Electronics 7 (25) doi:10.3390

Imeci, S.T., Sisman, I., and Demircioglu, E. 2011. 4.77 dB hybrid stripline coupler. 27th Annual Review of Progress in Applied Computational Electromagnetics, Williamsburg, Virginia, (CACES.

Hu J, Yong Z, Yupeng L, Tianhao R, Ruimin X, Quan X, Sub-Millimeter-Wave $10 \mathrm{~dB}$ Directional Coupler Based on Micromachining Technique, International Journal of Antennas and Propagation, Article ID 940212.

Salem, P., Wu, C. and Yagoub, M.C.E. 2006. Non-uniform tapered ultra wideband directional coupler design and modern ultra wideband balun integration. Proceeding of AsiaPasific Microwave Conference, 10.1109/APMC.

Imeci, S.T., Bayram, K.S., and Zeytinoğlu, A.Z. 2010. 20 dB hybrid stripline coupler. 26th Annual Review of Progress in Applied Computational Electromagnetics, Tampere, Finland, ACES.

Baek, D., Kim, Y.K. 2008. Symmetric microstrip interdigital capacitor-compansated high directivity directional-coupler. Microwave and Optical Technology Letters, 50 (11).

Asdhar, G.A., Wijanto, H. Nur, L.O. 2018. T-Junction branch line coupler with notch band filter for radar S-band $3 \mathrm{GHz}$. E-Proceeding of Engineeering, 5 (3), 4635.

Sonnet Suites, version 13.56, 2013. www.sonnetsoftware.com.

Tian, Z., Free, C., Barnwell, P., Wood, J., Aitchison, C. 2001. Design of novel multilayer microwave coupled-line structures using thick-film technology. Microwave Conference, 31st European, 10.1109/EUMA.2001.339144. 
Yildiz, A., Imeci, S.T. 2020. $30 \mathrm{~dB}$ microstrip coupler with high directivity. Sustainable Engineering and Innovation ISSN 2712-0562 vol. 2 (1) 26-33.

Yuksel, E. Imeci, S.T. 2012. 50 dB hybrid stripline coupler. 28th Annual Review of Progress in Applied Computational Electromagnetics, Columbus, Ohio, CACES.

Imeci, S.T. 2017. 3 DB Branchline Coupler. International University of Sarajevo, 49-62.

Nasri, M., Zarifi, D., Zaman, A.U. 2020. A wideband 3-dB directional coupler in GGW for use in V-Band communication systems. IEEE Access, 8 (5), 10.1109/ACCESS.2020.2968609.

Sorocki, J., Piekarz, I. 2020. Low-Cost microwave components fabrication in hybrid technology of laminates and additive manufacturing on an example of miniaturized suspended directional coupler. IEEE Access, 8 (2).

Tutuncu, B., Torpi, H., and Imeci, S.T. 2019. Directivity improvement of microstrip antenna by inverse refraction metamaterial. Journal of Engg. Research 7 (4) 151-164.

Dalar, K.C., Yıldırım, M., Aydın, M.A., and Imeci, S.T. 2012. 3dB hybrid coupler. 28th Annual Review of Progress in Applied Computational Electromanetics, Columbus, Ohio, ACES 